Marlène Thélusma Rémy, Contribution de la femme haïtienne à la construction et à la survie de son pays

\title{
Monica Blondi
}

\section{(2) OpenEdition}

\section{Journals}

\section{Edizione digitale}

URL: http://journals.openedition.org/studifrancesi/7747

DOI: 10.4000/studifrancesi.7747

ISSN: 2421-5856

\section{Editore}

Rosenberg \& Sellier

\section{Edizione cartacea}

Data di pubblicazione: 1 décembre 2009

Paginazione: 678-679

ISSN: 0039-2944

\section{Notizia bibliografica digitale}

Monica Blondi, «Marlène Thélusma Rémy, Contribution de la femme haïtienne à la construction et à la survie de son pays», Studi Francesi [Online], 159 (LIII | III) | 2009, online dal 30 novembre 2015, consultato il 09 janvier 2021. URL: http://journals.openedition.org/studifrancesi/77477 ; DOI: https:// doi.org/10.4000/studifrancesi. 7747

Questo documento è stato generato automaticamente il 9 janvier 2021.

\section{(c) $(1) \odot$}

Studi Francesi è distribuita con Licenza Creative Commons Attribuzione - Non commerciale - Non opere derivate 4.0 Internazionale. 


\title{
Marlène Thélusma Rémy, Contribution de la femme haïtienne à la construction et à la survie de son pays
}

\author{
Monica Blondi
}

\section{NOTIZIA}

MARLÈNE THÉLUSMA RÉMY, Contribution de la femme haïtienne à la construction et à la survie de son pays, Paris, L'Harmattan, 2008, pp. 154.

1 Questo saggio socio-antropologico nasce dall'esperienza diretta della sua autrice che per vent'anni, dal 1972 al 1992, ha svolto la professione di educatrice e assistente sociale. Il suo intento è principalmente quello di rendere omaggio alle donne haitiane di tutte le epoche e di tutte le classi sociali, soprattutto quelle nate e cresciute in un contesto rurale, vittime del maschilismo e di condizioni di vita particolarmente difficili. Lo studio si apre con una carrellata di ritratti femminili appartenenti all'epopea haitiana, a partire dalla capostipite, la regina indiana Anacaona, figura molto celebrata anche in letteratura; seguono poi le eroine che combatterono valorosamente al fianco degli uomini nelle lotte per l'indipendenza, come Suzanne Louverture, moglie del celebre eroe nazionale, la quale, deportata in Francia insieme al marito, subì la tortura senza mai tradirlo. Infine vengono celebrate le pioniere del movimento femminista haitiano nato attorno al 1950.

2 Ad Haiti le donne sono gravemente discriminate sia in famiglia che nella società. La svalutazione del femminile è fortemente radicata nella mentalità haitiana, legittimata anche da una tradizione orale che, attraverso proverbi che stigmatizzano alcuni tra $i$ difetti femminili più temuti dall'uomo, come la mancanza di razionalità $o$ l'inaffidabilità, contribuisce a trasmetterla di generazione in generazione, rendendo difficile ogni possibilità di cambiamento. La condizione della donna ad Haiti sembra basarsi su una contraddizione di fondo. Pur svolgendo un importante ruolo sia a livello 
economico che sociale, il suo impegno non viene riconosciuto né tanto meno retribuito. Infatti, oltre ad aiutare l'uomo nella semina e nel raccolto, la donna partecipa attivamente alla commercializzazione dei prodotti agricoli; inoltre ha l'onere dell'andamento domestico, dell'educazione dei figli e della cura degli anziani. Con il suo lavoro dà un forte impulso all'economia nazionale, tuttavia il suo contributo non è mai stato ufficialmente quantificato e, a differenza di quanto accade per l'uomo, neppure remunerato. E ciò perché nel mondo agricolo esiste una poligamia non legalizzata che consente all'uomo di avere più compagne che lavorano la terra per lui, senza avere alcun obbligo retributivo nei loro confronti. Nei villaggi, inoltre, il tasso di analfabetismo è più elevato tra le donne perché l'educazione scolastica viene riservata agli uomini. Ancora oggi, le giovani che non continuano gli studi vengono iniziate al lavoro molto presto dalle venditrici ambulanti più anziane. Costrette a portare pesi per lunghi tragitti fino alla città, bivaccando in luoghi sporchi e malsani, sono spesso vittime di malattie, come l'anemia, causate dalla malnutrizione. Inoltre, la disinformazione e l'ignoranza delle norme igieniche di base le espone al rischio dell'Aids.

Oltre al ruolo economico, la donna haitiana ha un importante ruolo sociale che consiste nello stringere relazioni. Fondamentali, perché di grande valore culturale, sono i rapporti tra diverse generazioni di donne. Quale depositaria di una tradizione ancestrale di valori, la donna sente su di sé la responsabilità di trasmettere questa eredità culturale alle generazioni future. Inoltre, è lei a curare i rapporti tra città e campagna, anche se l'inurbamento comporta il più delle volte un ulteriore sfruttamento, in qualità di domestica, o addirittura la degradazione, quando è costretta a prostituirsi. La svalutazione del femminile, in famiglia e nella società, impedisce alla donna di sviluppare un'immagine positiva di sé e di avere coscienza del proprio valore. L'unico ambito in cui riesce a sottrarsi alla tutela patriarcale è quello religioso. Le associazioni cattoliche e protestanti forniscono alla donna protezione e sostegno, ma è soprattutto nel vudù che può sperimentare una forma di emancipazione. Scegliendo di servire i loas, la donna accetta di aderire a un sistema «familiare» di tipo matriarcale che tende ad essere egualitario grazie alla divisione dei ruoli. La crisi di possessione, fase centrale della cerimonia vudù, esalta il ruolo della donna liberandola, seppure temporaneamente, dalla tutela maschile. 